\title{
AS LEITURAS DA FILOSOFIA DO DIREITO DE G.W. F. HEGEL: ENTRE HERMENÊUTICA E RECEPÇÃO
} READINGS IN THE PHILOSOPHY OF RIGHT BY
G.W. F. HEGEL: BETWEEN HERMENEUTICS
AND RECEPTION Agemir Bavaresco* Danilo Vaz-Curado** Paulo Roberto Konzen***

RESUMO - O artigo procura apresenta os argumentos centrais das principais correntes interpretativas da Filosofia Política de Hegel na Alemanha, França e no Brasil de forma a avaliar e demonstrar o potencial de diagnose de tal esforço teórico; ao mesmo tempo, objetivase demonstrar desde estes autores como uma análise da obra de Filosofia Política de Hegel revela-se atual mediante a articulação de seu sistema como um todo.

PALAVRAS CHAVE - Hegel. Filosofia. Hermenêutica. Lógica. Filosofia Política.

ABSTRACT - The article presents the central arguments of principals interpretations of Hegel's Political Philosophy in Germany, France and Brazil to assess and demonstrate the potential for diagnosis of such a theoretical effort, at the same time, we seek to demonstrate through such authors as an analysis of the Political Philosophy work of Hegel is revealed actual necessarily through the articulation of your system as a whole. KEYWORDS: Hegel. Philosophy. Hermeneutics. Logic. Political Philosophy.

\section{Introdução}

A Filosofia do Direito de Hegel, nas mais diversas tradições, ao longo da história, recebeu muitos tipos de leituras, o que ocasionou modos bem

* Doutor em Filosofia pela Universidade de Paris 1. Professor do PPG de Filosofia da PUCRS. Beneficiário de auxílio financeiro da CAPES-Brasil. Site: <www.abavaresco. com.br>.E-mail: <abavaresco@pucrs.br>.

**Doutorando em Filosofia pela UFRGS. Bolsista da CAPES-Brasil. E-mail: < danilo costaadv@hotmail.com>.

*** Doutorando em Filosofia pela UFRGS. Bolsista do CNPq-Brasil. E-mail: <prkonzen@ yahoo.com.br>.

\begin{tabular}{|l|l|l|l|l|l|}
\hline Veritas & Porto Alegre & v. 55 & n. 3 & set./dez. 2010 & p. 83-105 \\
\hline
\end{tabular}


diversos de interpretação. Neste trabalho, nosso objetivo se restringe a uma leitura de Filosofia Política dessa obra, de modo a correlacionar as formas hermenêuticas de sua abordagem aos modos de sua recepção, segundo o critério de selecionar alguns autores representativos que possam estabelecer um panorama amplo, mas sem sentido de exaustão, dos modos de leitura e impacto da Filosofia do Direito de Hegel na tradição filosófica. O problema a ser enfrentado no presente artigo, limita-se, assim, a identificar os principais interesses dessas leituras e propor algumas aproximações ou diferenças, visando proporcionar à comunidade filosófica um panorama seguro das principais vias interpretativas do corpus filosófico-político hegeliano.

No momento em que finalmente se concretiza a publicação da tradução brasileira da Filosofia do Direito ${ }^{1}$, é mais do que oportuno apresentar essas leituras, a fim de que os pesquisadores em geral, e os hegelianos e hegelianas em especial, situem-se nesse contexto e, ao mesmo tempo, ousem novas leituras dessa obra clássica da Filosofia ocidental.

Mas, urge observar que um dos aspectos centrais da Filosofia do Direito de Hegel consiste no estabelecimento das relações entre o lógico e o político ou o real. Eis o que partilham as formas de abordagem aqui escolhidas para iluminar a recepção existente e a vindoura. Ora, cabe distinguir e optar entre uma leitura da Filosofia do Direito de Hegel como um simples esboço político de seu tempo ou como um texto de Filosofia Política, em que se apresenta a vinculação essencial entre os âmbitos do ser e do dever-ser. Afinal, dependendo da análise, a Filosofia do Direito pode ser assimilada como uma mera representação ideológica da então realidade existente ${ }^{2}$. Deste modo, ao se analisar a obra de Hegel é preciso distingui-la de um mero tratado político e, assim, reconhecer e observar nela todas as relações sistemáticas, apontadas por Hegel, entre o lógico e o político ou o real, e as configurações que lhe dotam de inteligibilidade e que são próprias de um texto de Filosofia Política.

No intento de proporcionar instrumentos ao debate da Filosofia do Direito de Hegel, especialmente em sua face político-filosófica, optamos por dividir o texto em três correntes principais: uma alemã, centrada na figura de Joachim Ritter; outra francesa, em que se analisa a recepção da filosofia hegeliana por Bernard Bourgeois e Eric Weil; e, ainda, a

1 A tradução da Filosofia do Direito de Hegel, realizada por Paulo Meneses e outros doutores e doutorandos, contando com apresentação de Denis L. Rosenfield, foi lançada em outubro de 2010.

2 Cf. KONZEN, Paulo Roberto. O conceito de Estado e o de liberdade de imprensa na Filosofia do Direito de G. W. F. Hegel (Dissertação de Mestrado). Porto Alegre: UFRGS, 2008, p. 87. 
corrente brasileira, apresentando as leituras de Denis Rosenfield e Thadeu Weber.

Sem sentido de exclusão de outros autores, nos restringimos nestes cinco autores em vista de seu impacto no estudo da assim chamada Filosofia Prática em geral e da Filosofia Política centrada na Filosofia do Direito de Hegel em particular, bem como face ao fato de que tais recepções não se coadunam com os conhecidos clichês e modismos passageiros que diuturnamente assolam o debate filosófico.

\section{Leitura de filosofia política alemã}

A Filosofia Política de Hegel, tal como supramencionado na seção introdutória do artigo, sempre foi alvo de intensas discussões, tanto no âmbito da Hegel-Forschung, como na literatura não especializada. As acusações ${ }^{3}$ e os encômios ${ }^{4}$ à sua tradução conceitual da realidade política se amontoaram de modo a dificultar o acesso aos não iniciados sobre a sua própria obra, bem como obstacularizam o próprio posicionamento crítico das gerações posteriores sobre seu edifício conceitual.

Hegel como todo o filósofo, pela amplitude temática de suas abordagens, permite a discussão de suas ideias de diversas formas, seja pela reconstrução genética de seu itinerário, seja pela oposição temática de sua obra frente à tradição e aos seus contemporâneos, ou mesmo tomando-se sua obra como resposta às aflições de seu tempo. Hegel serve tanto aos intentos filosóficos de ordem aporética como às perspectivas filosóficas sistemáticas, sendo neste entorno recepcionada sua obra.

Todas essas formas de abordagem filosófica são explicáveis e, ao mesmo tempo, limitadas. Cientes de tal exercício, aqui propomos

3 Entre os opositores de Hegel e da sua Filosofia Política, em seus mais diversos motivos, podemos citar três autores e livros paradigmáticos: (i) Rudolf Haym, in Hegel und seine Zeit. Berlin: Verlag von Rudolf Gaertner, 1857; (ii) Hermann Heller, in Hegel und der nationale Machtstaatgedanke in Deutschland. Berlin: BG Teubner, 1921 e (iii) Karl Raimund Popper, in The Open Society and Its Enemies, V. 2: "The High Tide of Prophecy: Hegel, Marx and the Aftermath", Routledge, 1945. Neles Hegel é respectivamente apresentado como (i) um conservador político e filósofo do Estado prussiano, (ii) defensor do supremo poder do Estado [Staatsgewalt] e (iii) como um inimigo da sociedade plural e democrática.

4 Dentre os filósofos que buscaram avaliar positivamente o legado político hegeliano, podemos citar: (i) Karl Rosenkranz, in (a) Hegels Leben. Berlin: Duncker und Humblot, 1844 e (b) Apologie Hegels gegen Hernn Dr. Haym. Berlim: Duncker und Humblot, 1858, (ii) Joachim Ritter, in Metaphysik und Politik. Studien zu Aristoteles und Hegel. Frankfurt am Main: Suhrkamp, 1969 e (iii) Denis L. Rosenfield, in Politique et liberté. Une étude sur la structure logique de la „Philosophie du droit“ de Hegel. Paris: Aubier Montaigne, 1984. Neles respectivamente podem ser encontradas as chaves para o confronto com a maioria das teses negativas e pejorativas expostas na nota anterior. 
uma exegese que se restringe à compreensão do conceito de eticidade (Sittlichkeit), a partir de Hegel, porém sob o lastro da recepção de seu pensamento pela obra do filósofo alemão Joachim Ritter, especialmente das discussões contidas no livro Metaphysik und Politik.

Investigaremos como a eticidade se estrutura em Hegel, especialmente em sua Filosofia do Direito, e a explicitaremos mediante a tessitura argumentativa desenvolvida por Joachim Ritter, de modo a proporcionar a compreensão desse conceito fundamental, ao mesmo tempo unindo a exegese conceitual - de Hegel - à apropriação semântica contemporânea e potencial de diagnose - de Joachim Ritter - para, ao final, quiçá apresentarmos a atualidade de tal conceito.

Na sua Filosofia do Direito ${ }^{5}$, a Eticidade (Sittlichkeit) ocupa a terceira parte do livro, antecedida pelo Direito Abstrato e pela Moralidade, demarcando-se como o momento culminante da obra. Tomaremos a estruturação da eticidade num dúplice sentido: como momento de elevação (Erhebung) do Direito Abstrato e da Moralidade ao estágio da vida ética ou da eticidade e, ao mesmo tempo, também como suprassunção ${ }^{6}$ (Aufhebung) do espírito livre, momento máximo da Filosofia do Espírito Subjetivo, à vontade livre em si e para si, que quer a vontade livre como instituição autoconsciente do Espírito. É nessa dupla carga semântica que demarcaremos a (re)construção da eticidade (Sittlichkeit).

Poderíamos afirmar que a construção do conceito de eticidade em Hegel, especificamente em sua Filosofia do Direito, inicia seu estruturar-se mediante a união, sem dissolução das particularidades próprias a cada momento, da capacidade subjetiva dos agentes de se relacionarem com as coisas como pessoa, que se apropria e põe sua vontade sobre os objetos apropriáveis - no Direito Abstrato - e do atuar como sujeito, que se relaciona com outros sujeitos, justificando suas condutas e deliberações - na Moralidade.

Nesse contexto de estruturação por mais elevação (Erhebung) da eticidade na Filosofia do Direito, o Direito Abstrato é a conformação do agir face à norma sem a deliberação prática sobre a legitimidade ou não das determinações volitivas assumidas; ou seja, a ação (Handlung) é apropriada pela legalidade e seu efetivar-se, nesse momento, é o agir livre, enquanto mero atuar segundo a norma.

5 Utilizamos aqui a versão da Suhrkamp (1970), mas sempre comparando com a Felix Meiner (1967).

6 Para o conhecimento conceitual das divergências na Hegel-Forschung acerca da opção do uso deste vocábulo e suas implicações, bem como das demais possibilidades de tradução, Cf. PERTILLE, José Pinheiro. Faculdade do Espírito e Riqueza Material: Face e verso do conceito 'Vermögen' na Filosofia de Hegel (Tese de Doutorado), p. 62-81 e 240-241. 
A Moralidade eleva a ação das pessoas face ao Direito Abstrato ao status de sujeito de direitos, ao vincular o atuar à deliberação dos agentes face à lei, a qual é entendida não como a regra heterônoma da norma, mas como a lei autônoma do agir, justificando-a e responsabilizando-se perante seu atuar. Através da Moralidade, é desenvolvida na economia da Filosofia Política hegeliana a dupla capacidade de legitimação do agente, ao exigir a conformidade de suas ações face à lei e à sua deliberação interna, legitimando-o em face de outros sujeitos de direito, os quais também se autodeterminam mediante fins, ou seja, moralmente.

É em tal contexto de mútuo imbricamento de legalidade e de moralidade, realizado pela Erhebung dos momentos do Direito Abstrato e da Moralidade ao estágio da Eticidade, que se demarca o primeiro passo da Sittlichkeit, a saber, pela afirmação da subjetividade das pessoas como sujeitos livres, em que o universal do Estado e das instituições objetivas se identifica com a vontade subjetiva ${ }^{7}$.

É esta união entre legalidade e moralidade, recebida como herança da precedente filosofia kantiana, que determina o ponto de arranque do conceito hegeliano de eticidade desenvolvido na sua Filosofia do Direito ${ }^{8}$, que corresponde, na esfera das figurações históricas, à afirmação do princípio da subjetividade e do seu relacionar-se com as instituições, enquanto efetivação da vontade particular na e mediante a vontade geral ${ }^{9}$, equivalente no âmbito do desenvolvimento do conceito, à passagem (Übergang) do ponto de vista kantiano da legalidade e da moralidade à eticidade pelo percurso que se estende da família à sociedade civilburguesa e culmina no Estado ${ }^{10}$.

Hegel, ao tratar da constituição e do plano da obra, desdobra a eticidade nessa dúplice dinâmica de Erhebung e de Aufhebung, ao afirmar, na sua Filosofia do Direito, no § 33, letra "C", a eticidade como: (i) "a unidade e a verdade desses dois momentos abstratos" - do Direito Abstrato e da Moralidade - "a ideia em sua existência universal em si e para si"11, ao mesmo tempo em que especifica a carga semântica

7 Cf. RITTER, Joachim (1969). Metaphysik und Politik, p. 282.

8 Cf. RITTER, Joachim (1969). Metaphysik und Politik, p. 284-285: "Daher nimmt Hegel in der Rechtsphilosophie die Kantische Position von Legalität und Moralität zum Anfang und Ausgangspunkt".

9 É importante não confundir a posição hegeliana de Erhebung da legalidade e da moralidade em direção à eticidade e a posição de Kant, que, conhecendo a distinção entre legalidade e moralidade, limita o atuar livre à esfera do direito, como única forma e realidade da ação humana, não reconhecendo na moralidade o papel fundamental de legitimação do atuar jurídico ou secunda lege.

10 Cf. RITTER, Joachim (1969). Metaphysik und Politik, p. 289.

11 HEGEL (1970). Grundlinien der Philosophie des Rechts, Ed. Suhrkamp, § 33, p. 87. No original: "Die Einheit und Wahrheit dieser beiden abstrakten Momente (...) - die Idee in ihrer an und für sich allgemeinen Existenz; die Sittlichkeit". 
da eticidade como diversa da moralidade e até antinômica ${ }^{12}$, e (ii) o desdobrar internamente da eticidade, sob a forma de liberdade (Freiheit), enquanto substância ética (sittliche Substanz), que se desenvolve nas esferas concêntricas e interligadas da família, da sociedade civilburguesa e do Estado.

No Estado, do ponto de vista lógico, acontece o acabamento (Vollendung) que é a efetivação, no sentido de mais alto desenvolvimento do conceito de eticidade, através do mútuo reconhecimento da vontade singular nas diversas esferas de realização de seu Si com a vontade geral (volonté générale) do Estado, identificando-se o conceito e a atividade de suas configurações no ato de cada sujeito ético. Nesse estágio da eticidade, a substância ética é o próprio sujeito.

Essa realidade viva, que é a eticidade hegeliana, é apontada por Joachim Ritter (1969, p. 293-294) como o resultado da relação entre a Erhebung, movimento interno à obra de elevação dos conteúdos conceituais dos estágios mais imediatos e abstratos aos mais concretos, e a Aufhebung que, sendo também uma elevação interna à obra, conecta o desenvolvimento do conceito com um determinado conjunto de determinações do pensar, as quais estão se efetivando no tempo, v. g. o Direito (Recht), ao mesmo tempo em que demonstra como este desenvolvimento interno à obra é reciprocamente o desenvolvimento do Espírito (Geist) na sua exteriorização como História (Geschichte).

Nesse contexto, a suprassunção (Aufhebung) é um dos conceitos internos à Ciência do Direito (Rechtswissenschaft) no sentido hegeliano do termo, elevando-os do Direito Abstrato à Eticidade, bem como é a efetivação do princípio da liberdade, mediante a demonstração da efetivação de seu princípio na história pela narrativa conceitual de seu percurso da Grécia até a Alemanha do ano de 1820/21. Por isso, Hegel pode afirmar que os gregos eram éticos, mas que não conheceram a moralidade. A dissolução da eticidade grega e o emergir da subjetividade livre com o Cristianismo, através da corrupção ${ }^{13}$ dessa comunidade, desse todo ético, suprassume-se, permitindo o emergir do princípio da personalidade livre e da moralidade; não obstante, a moralidade que emerge como o princípio dos novos tempos, segundo Hegel, é limitada, por restringir-se à realização da vontade unicamente a determinações internas, sendo incapaz de correlacionar conceito e experiência, tempo e história, mundo e sujeito.

12 Cf. HEGEL (1970). Grundlinien der Philosophie des Rechts, Ed. Suhrkamp, § 33, p. 88. „[...] Moralität und Sittlichkeit, die gewöhnlich etwa als gleichbedeutend gelten, sind hier in wesentlich verschiedenem Sinne genommen."

13 Cf. RITTER, Joachim (1969). Metaphysik und Politik, p. 293. 
Ora, é nessa tensão da substância ética, corrompida pelo princípio da modernidade - a moralidade -, segundo Ritter (Id., p. 296-297), que ocorre a recuperação por Hegel de Aristóteles ${ }^{14}$ face a Kant, emergindo na concepção hegeliana o papel fundamental a ser desempenhado pela moralidade nas discussões acerca das condições de deliberação do agir livre e de sua conversão na eticidade, como condição de efetivação desse mesmo agir como télos da polis.

Para Ritter, a suprassunção (Aufhebung) das determinações do desenvolvimento conceitual do agir livre na história conduziu Hegel a buscar e introduzir os princípios da Filosofia Política aristotélica como reagentes e como contraposição ao formalismo moral kantiano, afirmando inclusive que "a Filosofia do Direito de Hegel exercita a correção desta $<$ abstração $>$. E para isso renova a ética das instituições própria da tradição da <Política > de Aristóteles, porém o faz de maneira tal que nesta é introduzido o grande princípio da subjetividade e da moralidade e a faz o seu sujeito"15.

$\mathrm{Na}$ presente leitura da eticidade hegeliana, que realizamos com Joachim Ritter, torna-se claro como a Sittlichkeit se opõe à separação kantiana entre virtude e direito ou moralidade e legalidade, ao introduzir o âmbito moral como próprio da efetivação das instituições éticas, contrabalançando o papel do agir individual e moral com o agir histórico e, portanto, ético e institucional, através da incorporação das aquisições morais epistêmicas, oriundas de Kant, não como privadas e restritas ao sujeito tomado de modo isolado, porém incorporadas no mundo do Direito e das instituições objetivas.

A atualidade do conceito hegeliano de eticidade, segundo esta leitura, reside no resgate elaborado por tal conceito do âmbito político, inscrevendo-o como critério de legitimação das ações privadas de seus sujeitos constituintes. Afinal, Hegel conheceu a separação entre legalidade e moralidade, mas, ao contrário de Kant, a reformulou sob os moldes de uma legalização da moral, em que as normas, - no sentido de lei positiva -, devem se justificar nos seus espaços de efetivação, como condição primeira de sua realização e a moralidade deve se interconectar entre os seus destinatários, vinculando-os subjetivamente, apenas na medida em que se faça reconhecer objetivamente.

14 Cf. RITTER, Joachim (1969). Metaphysik und Politik, p. 298, chega inclusive a afirmar categoricamente que a Filosofia do Direito de Hegel mantém a tradição aristotélica.

15 RITTER, Joachim (1969). Metaphysik und Politik, p. 300. „Die Rechtsphilosophie Hegels unternimmt es, dieser $>$ Abstraktheit $<$ zu korrigieren. Sie erneuert dafür die zur Tradition der $>$ Politik < des Aristoteles gehörige, institutionelle Ethik, aber so, dass sie das grosse Prinzip der Subjektivität und Moralität in diese einbringt und zu ihrem Subjekt macht". 
Segundo nossa análise, o diferencial da recepção de Joachim Ritter da obra de Hegel, em especial da sua Filosofia Política por intermédio de sua Filosofia do Direito, é a primordial atenção na constituição do conceito de eticidade da relação presente entre configurações históricas, como base para a efetivação do lógico no espiritual, e a introdução dos fundamentos do agir de base aristotélica, como recurso para agudizar a crítica de Hegel a Kant e reciprocamente iluminar Hegel e Aristóteles, introduzindo no conceito de eticidade, tal como elaborado por Hegel, um instrumental analítico de base aristotélica, que sem escamotear o pensamento hegeliano, o ilumina e realça seu potencial de atualidade.

Mas, é claro que tal recepção não está imune às críticas; contudo, seu potencial de atualidade e a atualização da semântica hegeliana por ela promovida são condição suficiente para o reconhecimento do vigor e da fecundidade de tal recepção.

\section{Leituras de filosofia política francesa}

Dentro da recepção francesa, escolhemos dois autores representativos da leitura hegeliana: Bernard Bourgeois, por descrever a biografia hegeliana como a formação de sua Filosofia Política, ao longo do tempo, e Eric Weil, por representar uma crítica aos prejuízos sobre a Filosofia do Direito de Hegel.

\subsection{O Pensamento Político de Hege/16: a leitura de Bernard Bourgeois}

Bourgeois apresenta, em dois capítulos, a Filosofia Política hegeliana. No primeiro, ele descreve a biografia de Hegel de Tübingen até Iena, sob o ponto de vista do desenvolvimento de sua Filosofia Política. No segundo, trata do pensamento da política, ou seja, uma reflexão propriamente de Filosofia Política conforme o viés hegeliano.

1) O desenvolvimento da Filosofia Política hegeliana: Nesse capítulo, Bourgeois apresenta o devir ou a formação da Filosofia Política hegeliana, começando por Tübingen (1788-1793). Ali, nasce o ideal hegeliano de Filosofia Política, pois, em Tübingen, ele pensa na polis grega, a cidade antiga, como espaço de vida, em que o cidadão pode realizar seu ser na harmoniosa totalidade. A Revolução Francesa é outro tema político capital desse período. Hegel festeja todos os anos a queda da Bastilha. Para Bourgeois, "se o pensamento da Revolução [Francesa] ficou vivo

16 BOURGEOIS, Bernard (1992). La Pensée Politique de Hegel. Paris: PUF. 
em Hegel, é que a realidade da vida permanecia revolucionária, no entanto, a Revolução [Francesa] não chegou a se ultrapassar numa feliz reconciliação" (1992, p. 31).

Em Berna (1793-1796), Hegel faz a crítica à religião com um duplo significado político: ela é uma manifestação da 'repolitização' do ser humano e um estímulo da ação política para realizar e restaurar a polis. Enfim, "os escritos teológicos de juventude permanecem em Frankfurt o que eles foram em Tübingen e Berna, escritos teológico-políticos com destinação 'política'” (Id., p. 48).

Em Frankfurt (1797-1800), Hegel começa a elaboração mais técnica do sistema; introduz os conceitos de tempo e de história, marcando a "laboriosa passagem da adolescência idealista ao realismo da idade adulta", no "sentido de que a liberdade é o espírito do tempo, o conteúdo do momento presente da necessidade" (Id., p. 59). Hegel não abandona o idealismo inicial, mas o faz reconhecer na realidade do tempo histórico.

Enfim, em Iena (1801-1807), ocorre a reconciliação da razão (Tübingen/ Berna) e da vida histórica (Frankfurt), instaurando assim o hegelianismo. "Em Iena, Hegel apreende a identidade da idealidade e da realidade, do conceito e do tempo, da razão e da história, da filosofia e da política" (Id., p. 63).

Hegel pensa o Estado não somente como uma estrutura, mas também como vida em movimento, ou seja, como uma concepção orgânica. No Sistema da Vida Ética, retoma-se o tema antigo do cidadão grego feliz, unido ao Estado imediato, com o tema do mundo atual, em que o cidadão é autossubsistente ou autônomo face ao Estado. No seu artigo sobre As diferentes maneiras de tratar cientificamente o Direito Natural (1802-1803), Hegel trata da relação entre Economia, Direito e Política, pois o mundo da propriedade e o do direito privado se emanciparam face ao poder estatal. A esfera da vida econômica será mais tarde chamada de sociedade civilburguesa. Na Filosofia do Espírito (1805), Hegel afirma que a vontade do indivíduo está em relação com a vontade da comunidade, rejeitando a teoria do contrato. A vontade geral é apreendida como uma força anterior e superior às vontades individuais. Na Filosofia Real, busca-se a mediação entre os extremos da concepção aristocrática e a monárquica. Inclusive, Bourgeois afirma: "A mediação entre os extremos está na opinião pública, 'verdadeiro corpo legislativo', expressando a vontade geral" (Id., p. 74).

Enfim, na Fenomenologia do Espírito (1807), descreve a experiência da consciência no curso da história. No capítulo VI, o Espírito é a consciência que está no mundo. Segundo Bourgeois, a Fenomenologia expressa o próprio itinerário de Hegel, isto é, a obra de Iena justifica o devir da trajetória hegeliana: "O entusiasmo de Tübingen pela bela totalidade imediata da pólis grega entra em tensão, em Berna, com o racionalismo 
abstrato do Eu", "opondo-se ao mundo cristão alienado", em seguida, afirma-se no "racionalismo concreto de Frankfurt". O jovem torna-se adulto e, nos trabalhos de Iena, a então totalidade ético-política é pensada junto com a liberdade subjetiva dos indivíduos. O grande desafio é a "conciliação racional da liberdade subjetiva e da totalidade substancial". Quando Hegel deixa Iena, em 1807, o problema político está posto e a solução se encontra esboçada em grandes linhas (cf. Id., p. 80-81).

2) A Filosofia Política de Hegel: Para Bourgeois, "a Filosofia Política de Hegel quer ser um pensamento da política real e se apresenta como uma crítica de todo pensamento que se propõe ditar suas leis à política, isto é, que se dá como exterior (ideável) e superior (ideal) à realidade política, enfim, que depende do entendimento separador" (Id., p. 85). O desafio é pensar o ser, ou seja, pensar o seu autodesenvolvimento. Por isso, pensar alguma coisa apenas sendo pensamento, oposta à realidade, é não pensála. "Pensar o ser, é pensar a identidade do ser e do pensamento como movimento pelo qual a identidade se diferencia nela mesma e a partir dela mesma, retomando sem cessar sua diferença, que é a realidade". A Filosofia afirma esta razão imanente no ser, no mundo natural e também no mundo ético: "A Filosofia não é uma reflexão exterior sobre a Coisa, mas o reflexo da reflexão interior" (Id., p. 91).

Porém, a Filosofia não é uma simples reprodução do ser-aí, do existente, mas ela é a concepção do que é, "isto é, a expressão do conceito do ser-aí, do ser-aí como conceito ou razão, enfim, disso que Hegel chama: das Wirkliche (o efetivo)". O efetivo é o sensível sentido, o existente racionalizado. Assim é preciso compreender a célebre afirmação: "O que é racional, isto é efetivo, o que é efetivo, isto é racional". Há certa impotência do outro da razão a deixar-se racionalizar e a elevar-se da simples existência empírica à efetividade racional. Essa impotência manifesta-se no nível da natureza e também da história. "A Filosofia pode reconciliar-se com a realidade, desenvolvendo nela o ser efetivo, idêntico à razão que está nela". Ela pode reconhecer a razão presente na história. A Filosofia Política de Hegel não é a justificação do empírico, mas é "conceber e apresentar o Estado como alguma coisa que é em si racional, de ensinar não como o Estado deve ser, mas como ele deve ser conhecido. Ela quer ser o reflexo fiel da racionalidade em ação no fenômeno político" (Id., p. 93).

Por fim, Bourgeois reporta-se à Filosofia do Direito de Hegel para abordar a sua Filosofia Política. Ele faz um comentário geral de toda a obra, iniciando com a célebre fórmula: "O Direito em geral diferenciase ele mesmo segundo os momentos da identidade: o Direito Abstrato, a diferença: a Moralidade (Moralität), e da identidade da identidade e 
da diferença: a vida ética [ou a eticidade] (Sittlichkeit)" (Id., p. 114). A partir desse princípio lógico, Bourgeois analisa as três partes da obra, caracterizando-se por uma leitura silogística em dois níveis: (i) identidade da identidade e da diferença e (ii) universalidade, particularidade e singularidade. Assim, o autor vai examinando cada parte da Filosofia do Direito, a partir dessa ótica de leitura. De fato, esse silogismo permite ao autor identificar a estrutura lógica do conceito político que atravessa toda a obra. Ele vai descrevendo a racionalidade imanente no desenvolvimento do conceito de vontade livre: "A política pensada filosoficamente é pensada como o meio efetivo, em que a razão, agindo no seu fenômeno histórico, retoma-se na sua interioridade e se realiza numa Filosofia Política" (Id., p. 140).

\subsection{Hegel e o Estado ${ }^{17}$ : a leitura de Eric Weil}

Eric Weil, no seu livro Hegel e o Estado, fruto da compilação de cinco conferências, faz uma leitura da Filosofia do Direito que rompe com "a crítica tradicional, segundo a qual Hegel seria o apologista do Estado prussiano e o profeta do que se chama frequentemente o estatismo" (1985, p. 7). Weil atém-se apenas à Filosofia do Direito, enquanto obra escrita pelo próprio autor. Isto não significa invalidar os adendos (Zusätze), compilados pelos alunos ou editores, enquanto tendo valor para interpretar o pensamento hegeliano. Porém, o problema é que alguns se servem desses registros das diversas lições (Vorlesungen) como ponto de partida, enquanto interpretações, fórmulas ou frases descontextualizadas para analisar a Filosofia Política hegeliana. No entanto, somente constitui autoridade o texto fixado pelo próprio autor. "Lá onde as 'lições' parecem contradizer os livros e os escritos, é preciso seguir estes, e lá onde há acordo entre os dois, os primeiros não nos ensinarão nada de novo (salvo sobre as aplicações do sistema aos domínios determinados da realidade): é, pois, ao mesmo tempo, mais correto e mais simples se ater aos textos publicados pelo próprio Hegel" (Id., p. 8, nota 1).

No primeiro capítulo, Weil mostra que a Filosofia Política hegeliana situa-se historicamente face aos diversos fatos, tais como a Revolução Francesa, o Terror Jacobino, as guerras napoleônicas, as Assembleias de Würtemberg, o Estado Prussiano, a Reformbill inglesa, etc. ${ }^{18}$. Diante de

17 WEIL, Eric (1985). Hegel et l'État. Paris: Vrin.

18 Hegel escreveu, propriamente, três Escritos Políticos, a saber: A Constituição da Alemanha (1800-1802); Atas da Assembleia dos Estados do Reino de Würtemberg (1815-1816) e A propósito da 'Reformbill' inglesa (1830). Os três escritos foram redigidos em datas cruciais da história da Europa e da Alemanha. Apresentam visão geral do pensamento político de Hegel num período de 30 anos, permitindo compreender que ele viveu a atualidade política, na imediatidade dos acontecimentos e sob a pressão da opinião pública. 
sua Filosofia Política, a crítica clássica é que sua Filosofia é reacionária. Aí se incluem os liberais (Haym), a extrema esquerda (Marx, Engels, Bauer), a direita (Schelling), os herdeiros do romantismo e a escola histórica de Savigny, etc. Atribui-se a Hegel ter legitimado o Estado Prussiano e daí ser acusado de conformismo e de conservador. Porém, afirma Weil, a Prússia na época representa para Hegel,

[...] o modelo da liberdade realizada, ao menos nos princípios, o Estado do pensamento, da liberdade de propriedade, da administração que depende apenas da lei, do Estado de direito. Em 1830, como em 1818, Hegel considera a Prússia como o Estado moderno por excelência (o que parece exato do ponto de vista da história) e a vê assim, porque ele a vê fundada sobre a liberdade (Id., p. 22).

No segundo capítulo, Weil trata dos fundamentos filosóficos da Política, a partir da Filosofia do Direito. Os fundamentos são os seguintes:

a) O efetivo e o racional: sobre a questão do efetivo e do racional, basta abrir a Lógica de Hegel para ver que, na sua terminologia, efetividade e realidade não se confundem, porque o real é apenas em parte efetivo, sendo a sua aparição ou fenômeno.

b) A pessoa, a propriedade, o direito e o sujeito: Hegel começa a falar da liberdade a partir de sua forma mais simples e abstrata através do Direito. A primeira expressão da vontade empírica natural é o direito de propriedade. Nesse ato, o indivíduo natural torna-se pessoa e afirma-se como pessoa. Mas, na vontade individual, a pessoa quer o universal e, por isso, de pessoa, ele se torna sujeito.

c) A vontade livre: o aspecto fundamental da Filosofia do Direito é a liberdade, ou seja, a vontade livre. A vontade dá-se um conteúdo, um fim que se realiza na realidade. A tese importante é que a vontade livre apenas se satisfaz buscando a liberdade numa organização racional, ou seja, a universalidade da liberdade. A Filosofia Política é a descrição da vontade racional, realizando-se na história da liberdade. A liberdade concreta não é o arbitrário do indivíduo, mas a liberdade numa comunidade livre, ou seja, no Estado como organização racional e universal da liberdade.

d) A ideia (Idee) de Estado histórico oposta ao ideal (Ideale) de Estado: a teoria do Estado histórico é a razão realizada. A Filosofia se ocupa do que é, ou seja, de sua época apreendida no conceito. A Filosofia não prescreve receitas ou ensinamentos que indicam como o mundo deve ser. Quando se fala do Estado não se trata de representar os Estados particulares, mas de focar a ideia de Estado. Todo Estado, por defeituoso que seja, carrega consigo os 
momentos essenciais de sua realidade. O Estado empírico pode ser imperfeito; o Estado concreto pode ser ultrapassado pela história; porém, não se podem julgar os Estados sem saber qual é a ideia de Estado (cf. Id., p. 24-42).

O terceiro capítulo versa sobre o Estado como realização da ideia ética. Afirma-se seguidamente, registra Weil, que o Direito e a Moral não contam para Hegel, pois os qualifica de abstratos. Mas, o fato de serem denominados de abstratos não significa que sejam falsos ou devessem ser eliminados. Ao contrário, são indispensáveis, ainda que incompletos, pois todo o desenvolvimento do conceito deve levá-los em consideração. O Direito realiza-se numa organização e a Moralidade é possível num sistema de valores. O Estado é livre, se o cidadão pode aí encontrar a satisfação de seus desejos e interesses (cf. Id., p. 43-54).

No quarto capítulo, Weil trata de outro fundamento da Filosofia Política hegeliana, isto é, a Constituição, a qual é, para Hegel, uma realidade viva e histórica que reconhece e inclui os direitos e os deveres dos cidadãos. Ela organiza os poderes de modo dialético: o legislativo, o administrativo, o soberano (o príncipe), o parlamento e a opinião pública. A Constituição representa um organismo que anima a família, a sociedade civil-burguesa e o Estado. Mas, qual é o Estado de Hegel? É o Estado fundado no princípio da liberdade, a saber, o Estado moderno. Aqui, o determinante é a Constituição, pois ela não constitui um mero ato jurídico, mas a organização do reconhecimento dos cidadãos (cf. Id., p. 55-71).

No quinto e último capítulo, o autor descreve as características do Estado moderno e conclui: "Hegel não é o filósofo da Prússia. Ele é o filósofo do Estado moderno, que analisou corretamente, indicando, com precisão, em que consiste a liberdade no Estado, quais as condições que o Estado deve preencher para ser o Estado da liberdade, Estado que realiza o pensamento moderno" (Id., p. 72).

A Filosofia do Direito termina com alguns parágrafos sobre a Filosofia da História e as relações internacionais. Aqui, trata-se da soberania externa e da guerra, das relações dos Estados modernos entre si. O progresso na história é medido pela expansão da liberdade. A marcha da história é uma sucessão de Estados dominantes, em que aparecem o herói, o cidadão e a populaça, a sociedade econômica e o trabalhador, a religião e o problema social. A crise do Estado moderno implica a necessidade de uma nova forma de Estado. Por isso, a compreensão do Estado existente é a prova da superação deste na história: "O Estado hegeliano morre: a prova disto é que a Filosofia hegeliana do Estado foi possível. Esta forma completou-se, porque penetrou a realidade, por isso ela deve ceder lugar, e o Espírito, no seu trabalho inconsciente e subterrâneo, tende para uma nova Wirklichkeit" (Id., p. 103). 
Pode-se dizer que Weil faz uma leitura isenta de prejuízos, respondendo a uma série de estereótipos hermenêuticos da Filosofia do Direito. Ele toma o próprio texto de Hegel, a fim de comprovar o que sustenta e desfazer muitos mal-entendidos. O livro, que reúne cinco conferências, tem o estilo argumentativo do contato direto com o público, atendendo as inquietações e as provocações do debate.

\section{Leituras de filosofia política brasileira}

A recepção da Filosofia do Direito de Hegel no Brasil é realizada por vários autores, em diversos momentos e segundo os mais distintos critérios exegéticos. Não é nossa intenção, neste artigo, fazer esta reconstituição histórica, ou mesmo apontar qual a melhor leitura no sentido da constituição de um monopólio da interpretação ${ }^{19}$ entre nós, porém, cabe destacar que a tradução desta obra marca um novo momento na recepção da Filosofia Política hegeliana em nosso país. Por isso, optamos por dois intérpretes: Denis Rosenfield e Thadeu Weber. Entendemos que eles fazem leituras com vieses específicos, que se complementam: uma mais lógica-política (Rosenfield) e a outra mais ético-histórica (Weber).

\subsection{Política e Liberdade em Hegel: a leitura de Denis Rosenfield}

O subtítulo "Um estudo sobre a estrutura lógica da Filosofia do Direito de Hegel" da obra Política e Liberdade em Hegel ${ }^{20}$ fornece a chave hermenêutica que Rosenfield usa para sua leitura. $O$ autor realiza uma análise das três partes da obra de Hegel, a partir do pressuposto de uma leitura lógica. Rosenfield propriamente acompanha as divisões da Filosofia do Direito de Hegel, analisando cada um dos capítulos e subcapítulos de tal obra. Tal roteiro, inclusive, serve de orientação para uma devida leitura histórica, crítico-filológica e hermenêutica de tal obra hegeliana.

\section{a) Contribuição Original}

Segundo afirmação de Pierre-Jean Labarrière, no "Prefácio", "a obra de Denis Rosenfield aporta para uma contribuição original para a nossa reflexão", a saber, que "Política e liberdade em Hegel, tendo como centro

19 Sobre os problemas que uma tal ortodoxia interpretativa pode ocasionar, é salutar o confronto e a leitura do texto de LÜBBE, Hermann. Hegels Kritik der politisierten Gesellschaft. In: Theorie und Entscheidung. Studien zum Primat der praktischen Vernunft. p. 93 e s.

20 O livro Política e Liberdade em Hegel (São Paulo: Ed. Brasiliense, 1983 e $2^{\mathrm{a}}$ ed. São Paulo: Ed. Ática, 1995) é a tradução da obra em francês: Politique et liberte: Une étude sur la structure logique de la "Philosophie du droit" de Hegel. Paris: Aubier, 1984. 
de análise a estrutura lógica deste pensamente político, é uma abordagem incomum para uma obra que trata da filosofia política de Hegel"; trata-se, como tal autor declara, da "relação, para dizê-lo brevemente, da política com a lógica" 21 . Tal aspecto é ressaltado, sobretudo, nas chamadas "distinções preliminares" expostas por Rosenfield, no início de sua obra, as quais, entre outras, caracterizam e diferenciam seu trabalho. Nelas, ele afirma:

A filosofia política de Hegel foi tratada de forma inadequada por uma tradição cuja preocupação central era, sobretudo, destacar o que considerava ser o controle autoritário, ou até totalitário, do Estado sobre o indivíduo. Assim, Hegel foi tido por um filósofo da Restauração, por um defensor do Estado prussiano, por um ideólogo da burguesia ascendente, etc. Pode-se dizer que sua filosofia política foi empobrecida à medida que a tornaram um simples pensamento político de seu tempo. Ironias da história, Linhas Fundamentais da Filosofia do Direito foi uma obra lida como produto de uma ciência particular. Apesar das múltiplas advertências feitas por Hegel aos que lêem a política desvinculando-a de sua relação com o todo, sua própria obra foi também submetida a tal segmentação. Com efeito, esta tradição separou a filosofia do político, o conceito do tempo ${ }^{22}$.

Ou seja, para Rosenfield, é necessário notar o "ponto central da filosofia política de Hegel, ou seja, as relações entre o lógico e o político"; inclusive, declara que "analisar-se-á o que foi publicado pelo próprio Hegel, pois é a única forma de se apreciar a significação lógica das categorias políticas" ${ }^{23}$. Segundo o autor, cabe "estabelecer um paralelismo entre a estrutura da Ciência da Lógica e a estrutura da Filosofia do Direito", para chegar ao "encadeamento lógico da Filosofia do Direito"24. Afinal, como afirma, "a lógica desta obra [Filosofia do Direito] é, na verdade, uma lógica do político que repõe a lógica da Lógica. Em outras palavras, a Filosofia do Direito é não somente produtora de uma lógica própria, mas verifica

${ }^{21}$ LABARRIÈRE, Pierre-Jean. "Prefácio". In: ROSENFIELD, D. L. Política e Liberdade em Hegel [1983]. p. 7-11.

22 ROSENFIELD, D. L. Política e Liberdade em Hegel [1983]. p. 14.

23 ROSENFIELD, D. L. Política e Liberdade em Hegel [1983]. Comentário da nota 1, p. 278: Também, cf. ROSENFIELD, D. L. "Invertendo a inversão ou lendo Marx a partir de Hegel". In: Revista Filosofia Política - 1. São Paulo: L\&PM, 1984. p. 28-30: "a ordem de determinação destas determinações-de-reflexão dependerá da esfera do real na qual elas se desdobram e, historicamente falando, da contingência de sua realização. Desconsiderar este componente lógico central da Filosofia do Direito tem como resultado a sua assimilação a um tratado político qualquer, mera representação "ideológica" do existente. (...) Não é arbitrário que a filosofia política de Hegel apareça como uma filosofia do direito pois, para ele, o político é o que provém da "polis", que a institui no seu movimento de determinação de si e que, portanto, não pode ser confundido com o que Marx considera como a política hegeliana, ou seja, a política autoritária e mistificada do Estado".

24 ROSENFIELD, D. L. Política e Liberdade em Hegel [1983]. p. 28. 
e realiza os princípios lógicos universais" ${ }^{25}$. Assim sendo, em resumo, segundo Rosenfield, "a questão que preocupa Hegel é de apreender a lógica imanente de qualquer conteúdo político" 26.

Por isso, cabe distinguir e optar entre uma leitura da Filosofia do Direito de Hegel como um simples esboço político de seu tempo ou como um texto de Filosofia Política, em que se apresenta a vinculação intrínseca entre o lógico e o político. Ora, dependendo da forma de consideração, a Filosofia do Direito de Hegel pode ser assimilada como um simples tratado político, enquanto mera representação ideológica do existente. Sobre isso, Rosenfield afirma, por exemplo, que "uma leitura atenta do texto hegeliano evidencia claramente - e Hegel o diz claramente - que se trata do conceito pensado do Estado e não das suas origens históricas ou das formas estatais vigentes em sua época"; afinal, o dito "caráter "divino" do Estado não é o de um Estado historicamente existente, mas o de seu desenvolvimento lógico" 27 . Sobre isso, seguem abaixo outras considerações:

O problema consiste em analisar as relações entre o conceito e o tempo, entre o lógico e o histórico. A identificação de um com o outro permite, de um lado, mostrar que o espírito é tempo e que o conceito forma-se historicamente, mas, por outro lado, esta identificação pode também resultar na concepção falsa, mas vulgarizada, do sistema hegeliano como um sistema fechado que expressaria o fim da história. Logo, a presente abordagem do texto evita considerar o conceito como desdobrando-se intemporalmente fora da história, ou como identificando-se completamente com ela, legitimando assim um Estado dado, ou fechando no tempo a sua evolução ${ }^{28}$.

Para Rosenfield, "não se trata de legitimar o existente, mas de elevá-lo à sua determinação lógica"; afinal "identificar a história conceitual dos acontecimentos significa tornar idêntico o que é, entretanto, diferente: a imanência do conceito com a exterioridade do acontecimento"; inclusive, o autor afirma que "o pensamento filosófico distingue-se essencialmente de toda forma de narração histórica, que permanece atada ao que acontece na sucessão aparente das coisas do mundo"; enfim, em suma, "trata-se para Hegel de apreender como o conceito surge no desenrolar de sua própria sucessão temporal" 29 .

\section{b) Efetividade e Racionalidade, Pensamento e Crítica}

Além disso, cabe realçar a exposição e a análise de Rosenfield dos conceitos hegelianos de efetividade, racionalidade, pensamento, crítica, eticidade, liberdade, cidadania, Estado etc., pois são elementos centrais

25 ROSENFIELD, D. L. Política e Liberdade em Hegel [1983]. p. 29.

26 ROSENFIELD, D. L. Política e Liberdade em Hegel [1983]. p. 33.

27 ROSENFIELD, D. L. Política e Liberdade em Hegel [1983]. p. 219.

28 ROSENFIELD, D. L. Política e Liberdade em Hegel [1983]. p. 60.

29 ROSENFIELD, D. L. Política e Liberdade em Hegel [1983]. p. 19; p. 21; p. 22; p. 61. 
da Filosofia do Direito de Hegel. Ora, sobre isso, por exemplo, Rosenfield afirma:

Pela cultura o indivíduo afasta-se das determinações puramente naturais e consegue apreender-se subjetivamente em uma objetividade que, de um lado, o formou e que, de outro, ele contribui para formar. O indivíduo é cultural, temporal, em seu processo de determinação de si, o que lhe dá a possibilidade de considerar criticamente o próprio processo de educação. A educação (formação) para a liberdade é, então, necessariamente produto de uma concepção do indivíduo que não privilegia uma de suas determinações em detrimento de outras. (...) A filosofia hegeliana é o contrário de uma filosofia que afirmaria o princípio da passividade dos cidadãos. É somente pela atividade e pela consciência dos cidadãos que o conceito atualiza-se, libera-se, no devir dos acontecimentos históricos. (...) A liberdade é antes de mais nada tributária de uma subjetividade (individual e conceituada) cuja determinação consiste em reconhecer como verdadeiro somente aquilo que foi preliminarmente submetido do exame à experiência e à crítica. (...) a segunda natureza do homem é a história ética do indivíduo, isto é, a história do movimento ativo dos indivíduos chegando à consciência de si mesmos como membros de uma comunidade. (...) é somente esta imbricação entre o homem e o ético que possibilita pensar a liberdade como pleno exercício da racionalidade contida em qualquer indivíduo. É pela autoconsciência da racionalidade inscrita nas relações éticas de uma época que caminha a ideia da liberdade ${ }^{30}$.

Rosenfield apresenta, inclusive, a ideia da liberdade como o objeto principal da Filosofia de Hegel:

Sem o direito à diferença, o Estado não pode ser uma unidade livre, pois o Estado só é livre através do movimento de produção de suas diferentes figuras. O direito à diferença deve ser concretamente pensado no interior de uma unidade que se faz plural. Consequentemente, não se pode afirmar que Hegel privilegia uma universalidade estatal que se imporia autoritariamente aos indivíduos, que são a alma do Estado. Uma universalidade estatal que não respeitasse os direitos da vontade particular poderia ser tudo, menos a concretização da ideia da liberdade, o que constitui propriamente o objeto da pesquisa filosófica de $\mathrm{Hegel}^{31}$.

Para Rosenfield, no Estado efetivamente segundo o seu conceito, no Estado ético, em resumo, todo cidadão reconhece e vem a realizar efetivamente sua vontade subjetiva, contudo, não mais na sua forma meramente imediata, mas, sim, antes mediada pelos interesses dos outros cidadãos ${ }^{32}$. Por fim, cabe ainda destacar que:

30 ROSENFIELD, D. L. Política e liberdade em Hegel [1983]. p. 47; p. 50; p. 100; p. 143.

31 ROSENFIELD, D. L. Política e liberdade em Hegel [1983]. p. 224.

32 ROSENFIELD, D. L. Filosofia política e natureza humana. Porto Alegre: L\&PM, 1990. p. 231: "os homens, em um sentido hegeliano, reconhecem-se como livres participantes, o que significa que esta forma de vida política é resultado de uma livre construção das relações humanas". 
A prática da cidadania exige a publicidade dos debates parlamentares, pois eles não são propriedade de um grupo de indivíduos isolados do resto do povo. Hegel opõe ao segredo das deliberações e debates o seu caráter essencialmente público. A opinião pública tem o direito de ser in-formada. (...) Um povo bem informado é um povo que não se deixa manipular ${ }^{33}$.

Ou seja, em um Estado devidamente formado e, por isso mesmo, esclarecido, forte, não há necessidade de impedir ou punir as externações.

As proibições dirigidas contra a liberdade de imprensa ocorrem quando o Estado afasta-se do seu conceito, um afastamento que, de todo modo, não deve restringir o livre exercício do pensamento. Poder-se-ia dizer que Hegel tem em vista o nível concreto de uma atividade jornalística cujo fim seria aproximar-se cada vez mais de critérios propriamente científicos, sabendo contudo que o ideal filosófico de uma opinião pública permanecerá sempre um ideal, pois a crônica de um instante está submetida aos seus acasos. Isto, no entanto, não deve impedir um trabalho de conscientização da opinião pública, pois o que está em jogo é a conscientização do direito de dizer não. (...) A história o contradisse, embora ele tivesse logicamente razão. Historicamente, o Estado se impôs contra o exercício da liberdade individual, ou, em todo caso, não contribuiu para o seu desenvolvimento ${ }^{34}$.

Rosenfield reitera várias vezes tal aspecto hegeliano ${ }^{35}$, mostrando que Hegel foi um defensor do princípio da liberdade, aliado com o da responsabilidade, o que, entre outros, vem a constituir o que é propriamente uma vida ética ou a eticidade.

\subsection{Thadeu Weber: Hegel - Liberdade, Estado e História}

O livro Hegel: Liberdade, Estado e História destaca um modo de leitura do corpus hegeliano, centrado especificamente na ideia de liberdade como tema central da Filosofia Política de $\mathrm{Hegel}^{36}$, com a peculiaridade de

33 ROSENFIELD, D. L. Política e Liberdade em Hegel [1983]. p. 258.

34 ROSENFIELD, D. L. Política e Liberdade em Hegel [1983]. p. 260-261.

35 ROSENFIELD, D. L. A democracia ameaçada: o MST, o teológico-político e a liberdade. Rio de Janeiro: Topbooks, 2006. p. 87: "Em linguagem hegeliana, teríamos o processo de autodeterminação do indivíduo, sua autonomia. Não há verdadeiro procedimento democrático que não tenha em sua base a liberdade de expressão e de pensamento, em que cada um possa dizer o que pensa, discordando dos governantes e criticando os que estão no poder. Essa liberdade de expressão vem acompanhada da liberdade de manifestação, que se concretiza no ir à rua, na organização dos que têm propósitos políticos comuns, podendo culminar em clubes ou partidos políticos. A liberdade de expressão se concretiza na liberdade de imprensa, na liberdade dos meios de comunicação em geral, de modo que a pluralidade possa ser efetivamente exercida, em que os cidadãos possam formar a sua opinião. Logo, torna-se necessária a existência de um conjunto de instituições jurídicas, de leis, que assegurem essas formas de liberdade, sem as quais todo ritual democrático seria um mero jogo de aparências".

36 Cf. WEBER, Thadeu. Hegel: Liberdade, Estado e História. Petrópolis, RJ: Vozes, 1993. p. 9. 
responder à pergunta fundamental acerca do que é necessário (Notwendig) e do que é contingente (Zufallig) no sistema hegeliano, e como ocorre a mediação entre estes pólos opostos através das determinidades da particularidade contingente e da universalidade necessária.

Ao constituir o plano de sua obra, como resposta às duas grandes correntes interpretativas, as quais liam Hegel, ora (i) como um necessitarista, em que a liberdade se definia como interiorização da necessidade, e por vezes (ii) como um sistema da liberdade, beirando o irracionalismo, Thadeu Weber consegue constituir uma leitura acerca de Hegel especificamente atraente e inovadora, porém que não se limita apenas à exegese e à recepção, mas coloca-nos em um papel de destaque na Hegel-Forschung.

A tese principal do livro é que o sistema hegeliano pode ser lido como um sistema coerente da progressiva efetivação da liberdade, desde que se coordenem a leitura de seus pressupostos lógicos presentes na Ciência da Lógica com as configurações da Filosofia do Espírito Objetivo.

O novo nesta leitura que segue o próprio espírito do pensamento hegeliano, tal como posto no $\S 1^{\circ}$ da Filosofia do Direito, é o papel explicativo central que joga a leitura da Lógica da Essência em sua seção Efetividade, em que coexistem a necessidade e a contingência objetiva, e não na Lógica Subjetiva, seção do Conceito, como ordinariamente as leituras eram feitas.

A obra de Thadeu Weber divide-se em quatro capítulos, os quais respectivamente apresentam (a) as formas de recepção e de leitura da ideia de liberdade, tal como desenvolvida em Hegel e recepcionada pela tradição filosófica; (b) a ligação entre os dois grandes troncos sistemáticos em Hegel, a doutrina do Espírito Subjetivo àquela do Espírito Objetivo; (c) no terceiro capítulo, nos é apresentado um grande mapeamento no seio da doutrina do Espírito Objetivo das passagens que demonstram o racional e o efetivo em face daquelas em que se explicitam apenas determinações inefetivas. Neste terceiro capítulo, que poderíamos chamar do núcleo de força do livro, somos convidados a percorrer toda a extensão da Filosofia do Direito de Hegel, do Direito Abstrato à Eticidade, passando pela Moralidade, em que o autor brinda-nos com a lapidação conceitual que nos permitirá encontrar o contingente no seio mesmo das determinações necessárias.

No quarto capítulo $(d)$, demonstra-se o desenvolvimento da ideia de liberdade na história e o sentido da expressão hegeliana de que a razão governa o mundo, de modo a assinalar como o progresso na história não se situa numa apreensão linear de percurso e desenvolvimento, e como o sujeito é agente histórico e não mero espectador do agir da razão no mundo. 
A leitura de Weber ao propor reconstruir o movimento do ser-aí da liberdade, mas não se limitando à relação entre o real e as estruturas de sua explicitação no seio do caminho que vai do indivíduo ao Estado, porém ampliando-o à história, oferece-nos uma abordagem que busca compreender a totalidade da Teoria do Espírito Objetivo hegeliano, articulando o agir do indivíduo, enquanto burguês, e do sujeito, enquanto cidadão, não apenas no seio da escritura institucional do Estado moderno, mas também no processo mesmo de liberação da liberdade de suas determinações negativas e dialéticas, para uma apreensão positivoracional do ser-aí da liberdade.

Por fim, nos diz Thadeu Weber, que todo o seu percurso de reconstrução e de iluminação da liberdade no Espírito Objetivo hegeliano nos conduz a uma conclusão co-extensível com a tarefa da Filosofia como um todo, pois

A Filosofia, diante disso, tem, hoje, a importante função de ensinar a distinguir o que é necessário e o que é contingente e, dentro do contingente, indicar o que é uma boa contingência e que, portanto, deve ser conservada, e o que é uma má contingência e que, portanto, deve ser eliminada ${ }^{37}$.

O projeto weberiano conduz a uma verdadeira epifania do Espírito Objetivo na busca da construção e autoexplicitação do itinerário da razão na história, enquanto governo do que é inteligível sobre o que se move pelo acaso, e não da racionalidade que predestina o curso do mundo, como outrora fora lido o sistema hegeliano.

\section{Conclusão}

Após a apresentação desses autores e dessas obras, percebe-se que a recepção da Filosofia do Direito, tanto na Alemanha, na França como no Brasil, tem um aspecto conjuntural ligado ao contexto hermenêutico e, ao mesmo tempo, um aspecto de escolha de ótica de leitura. Constatase que as leituras escolhidas, na recepção alemã, francesa e brasileira da Filosofia do Direito de Hegel, apresentam os citados aspectos e põem problemas de Filosofia Política, a saber:

a) A leitura de Joachim Ritter coloca o problema clássico da relação do indivíduo e do Estado, ou seja, em que medida é possível conciliar o contratualismo e a prioridade do todo sobre as partes? Ao lançar mão do movimento conceitual de elevação e suprassunção, Ritter interpreta dialeticamente essa relação de tal forma que o sujeito e o cidadão participam no Estado em seus níveis apropriados. Assim, essa leitura inclui a legitimação das ações privadas dos sujeitos.

37 WEBER, Thadeu. Hegel: Liberdade, Estado e História. Petrópolis, RJ: Vozes, 1993. p. 244. 
Pois a legalidade e a moralidade são reformuladas nos seus espaços de efetivação, como condição de sua realização. De fato, Direito Abstrato e Moralidade reconhecem os seus destinatários, vinculando subjetivamente apenas na medida em que se faça reconhecer objetivamente, a saber, na Eticidade.

b) A leitura de Bernard Bourgeois, de um lado, mostra que a Filosofia Política está vinculada à trajetória biográfica do filósofo e, de outro, que a Filosofia Política hegeliana insere-se na matriz do ser e não do dever-ser político, bem-entendido. Seria Hegel um filósofo que legitima qualquer realidade política dada? Ao defender a tese de que a razão se reconcilia com o ser, Hegel não está justificando o status quo político. Essa dita "reconciliação", segundo Bourgeois, dá-se pelo processo dialético em que a realidade é mediatizada pelo conceito do Estado. Apenas o que é efetivamente livre é conforme ao conceito. Então, o que é real embora já tenha o conceito imanente da liberdade, não significa que ele corresponda ao que é efetivamente livre.

c) A leitura de Eric Weil coloca a questão de voltar ao texto de Hegel. A leitura da Filosofia Política hegeliana estava contaminada por muitos preconceitos pelo fato de tomar como ponto de partida textos não escritos propriamente por Hegel. Weil tem o mérito de mostrar, partindo da própria Filosofia do Direito, que Hegel é um defensor do princípio da liberdade, ao contrário do que se repetia então e, muitas vezes, ainda continua sendo dito: a acusação de estatismo reacionário e de legitimador de toda espécie de totalitarismos. Qual é a lógica da ideia de liberdade, que se determina como vontade livre, nos seus níveis estruturais e garante o pleno reconhecimento à pessoa do Direito Abstrato, ao sujeito da Moralidade e ao membro ou ao cidadão da Eticidade, a plena efetivação de sua vontade nas instituições da liberdade? Esse problema da Filosofia Política é descrito por Weil, ao ler a Filosofia do Direito de Hegel para além dos clichês hermenêuticos reducionistas.

d) A leitura de Denis Rosenfield explora a intrínseca relação entre lógica e política, buscando expor a inteligibilidade imanente aos processos institucionais e a racionalidade que os orienta, tal qual uma relação de ampliação e de correspondência entre a Ciência da Lógica de Hegel e a sua Filosofia do Direito, e neste percurso apresentar a atualidade e a força hermenêutica da Filosofia Política hegeliana.

e) Thadeu Weber convida-nos ao desafio de perquirir a lógica que desvela a existência ou não de uma causalidade livre na 
Filosofia Política de Hegel, capaz de fazê-la uma doutrina ética com pretensões de atualidade e, para tanto, percorre as raízes e pontos nodais do sistema hegeliano, com ênfase prioritária para a Filosofia do Espírito Objetivo, concluindo que, com ressalvas, pode-se sim visualizar Hegel como filósofo da liberdade.

No sentido do corte epistemológico, aqui escolhido, cabe ressaltar como as leituras analisadas buscam correlacionar a dinâmica postulada por Hegel da ideia desenvolvendo-se mediante a atividade do conceito e de sua efetivação. É esta premissa que anima as leituras apresentadas, a saber, demonstrar como Hegel foi capaz de apreender o seu tempo em conceitos, não reduzindo a Filosofia Política a uma colcha de fatos e de descrições institucionais sem um fio condutor, capaz de uni-los ao passado e de impulsioná-los ao presente, não esgotando sua análise numa descrição empírica do real.

Da correlação entre conceitos lógicos e configurações empíricas ou entre a ideia e a história, sem desacoplar o lógico do político ou real, nem reduzir o lógico a uma afirmação fatalista da realidade, buscamos demonstrar a atualidade e o potencial de diagnose das leituras realizadas. Mediante o resgate, sobretudo, dos conceitos de eticidade (Ritter), de desenvolvimento, gênese e núcleo duro dos conceitos políticos, nas diversas fases e instâncias do pensar hegeliano (Bourgeois), e da devida colocação da economia e do papel do Estado na Filosofia Política de Hegel (Weil), da relação entre o lógico e o político (Rosenfield) e da busca por uma causalidade livre (Weber), constatamos que Hegel se torna atual e propício a nos auxiliar na tormentosa tarefa de compreensão do nosso espírito do tempo (Zeitgeist), como condição político-filosófica fundamental.

\section{Referências}

BOURGEOIS, Bernard. La Pensée politique de Hegel. Paris: PUF, 1992.

HAYM, Rudolf. Hegel und seine Zeit. Berlin: Verlag von Rudolf Gaertner, 1857.

HEGEL, Georg Wilhelm Friedrich. Grundlinien der Philosophie des Rechts. Frankfurt am Main: Suhrkamp, 1970.

. Filosofia do Direito. Trad. Paulo Meneses e outros. São Paulo: UNISINOS/

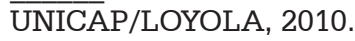

HELLER, Hermann. Hegel und der nationale Machtstaatgedanke in Deutschland. Berlin: BG Teubner, 1921.

KONZEN, Paulo Roberto. O conceito de Estado e o de liberdade de imprensa na Filosofia do Direito de G.W.F. Hegel. Dissertação de Mestrado. Porto Alegre: UFRGS, 2007.

LABARRIÈRE, Pierre-Jean. "Prefácio". In: ROSENFIELD, Denis L. Política e liberdade em Hegel. São Paulo: Brasiliense, 1983. 
LÜBBE, Hermann. Hegels Kritik der politisierten Gesellschaft. In: Theorie und Entscheidung. Studien zum Primat der praktischen Vernunft. Rombach Verlag: Friburg, 1971, p. 93-110.

PERTILLE, José Pinheiro. Faculdade do Espírito e Riqueza Material: Face e verso do conceito 'Vermögen' na Filosofia de Hegel. Tese de Doutorado. Porto Alegre: PPGFil, 2005.

POPPER, Karl Raimund. The Open Society and its Enemies. Vol. 2: The High Tide of Prophecy: Hegel, Marx and the Aftermath. London: Routledge, 1945.

RITTER, Joachim. Metaphysik und Politik. Studien zu Aristoteles und Hegel. Frankfurt am Main: Suhrkamp, 1969.

ROSENFIELD, Denis L. Politique et liberté. Une étude sur la structure logique de la "Philosophie du droit" de Hegel. Paris: Aubier Montaigne, 1984. . Política e liberdade em Hegel. São Paulo: Brasiliense, 1983.

. A democracia ameaçada: o MST, o teológico-político e a liberdade. Rio de Janeiro: Topbooks, 2006.

. "Invertendo a inversão ou lendo Marx a partir de Hegel". In: Revista Filosofia Política, São Paulo: L\&PM, 1 (1984).

ROSENKRANZ, Karl. Hegels Leben. Berlin: Duncker und Humblot, 1844.

. Apologie Hegels gegen Herrn Dr. Haym. Berlin: Duncker und Humblot, 1858.

WEBER, Thadeu. Hegel: Liberdade, Estado e História. Petropólis: Vozes, 1993.

WEIL, Eric. Hegel et l'État. Paris: Vrin, 1985. 